\title{
Análise parcial sobre a cerâmica arqueológica do Vale do Taquari, Rio Grande do Sul
}

\section{(Partial analysis of the archaeological pottery from Vale do Taquari, state of Rio Grande do Sul, Brazil)}

\author{
N. T. G. Machado ${ }^{1}$, P. Schneider ${ }^{2}$, F. Schneider ${ }^{3}$ \\ ${ }^{I}$ R. Leovegildo Leal de Moraes 75, Parque Novo Horizonte, Santa Maria, RS 97110-820 \\ ${ }^{2} R$. Coronel José Diel 746, Centro, Santa Clara do Sul, RS 95900-000 \\ ${ }^{3} R$. General Netto, sala 3, prédio 388, Cruzeiro do Sul, RS 95930-000 \\ nelitgm@terra.com.br
}

\begin{abstract}
Resumo
A pesquisa arqueológica pré-colonial desenvolvida na região que compreende a bacia hidrográfica do Rio Taquari/Antas identificou a ocupação de grupos horticultores ceramistas, que habitavam e percorriam o território, antecedendo em dez séculos a chegada dos primeiros colonizadores e imigrantes europeus. A presença de evidências cerâmicas, foco desse estudo, pontua e comprova a ocupação deste território. A coleção de fragmentos cerâmicos foi analisada com tabelas tecno-tipológicas identificando-se as características específicas de cada peça, modo de produção, tratamento de superfície incluindo a pintura e os desenhos geométricos. Deste modo se caracterizará a cultura material cerâmica desta região. A produção das vasilhas cerâmicas por grupos culturais atesta ocupações humanas no interior do Rio grande do Sul, antes da chegada do imigrante europeu e criam-se hipóteses sobre as práticas de vivência dessas ocupações.
\end{abstract}

Palavras-chave: cerâmica pré-colonial, horticultores.

\begin{abstract}
The archaelogical research about pre-colonial times developed in Vale do Taquari (Taquari/Antas hydrograpical basin) has identified the occupation of horticulturist and ceramist groups that inhabited the territory, preceding in ten centuries the european arrival. The presence of pottery evidences, the purpose of this study, proves the occupation of this territory. The fragmented pottery collection was analysed with technical-typological tables, where it was possible to identify specific characteristics of each evidence, mode of production, treatment on surface including painting and geometrical drawings. This way, it will be characterized the material culture (pottery) of this region. The pottery production made by cultural groups proves past human occupations in the state of Rio Grande do Sul, before the european arrival and it creates hypothesis about living practices of these occupations.
\end{abstract}

Keywords: pre-colonial pottery, horticulturists.

\section{INTRODUÇ̃̃O}

As evidências arqueológicas de povos ceramistas encontram-se entre as principais formas de sinalizar sítios arqueológicos pré-coloniais, ocupados preteritamente por grupos culturais que desenvolviam uma economia de horticultura. A maioria das peças arqueológicas em cerâmica é fragmentada e erodida, considerando, nesse caso, o grau

${ }^{\prime}$ Coordenadora do Setor de Arqueologia do Museu de Ciências Naturais da UNIVATES, Doutora em Arqueologia Brasileira pelo MAE/USP, Professora e membro do Colegiado do Mestrado em Ambiente e Desenvolvimento da UNIVATES, Lajeado, RS.

${ }^{2}$ Graduanda do curso de Licenciatura em História da UNIVATES, Bolsista de Iniciação Cientifica BIC Funadesp e Procoredes FAPERGS.

${ }^{3}$ Graduanda do curso de Licenciatura em História da UNIVATES, Bolsista de Iniciação Cientifica BIC FAPERGS. de integridade dos sítios arqueológicos com características de horticultura.

A cerâmica corresponde ao reflexo do comportamento social do grupo que as produziu, sendo, inclusive, uma delimitadora funcional na medida em que são as mulheres que as produzem. Produção e utilização do vasilhame ligamse diretamente às atividades alimentares, necessidade básica de sobrevivência, envolvendo e entrelaçando os indivíduos do grupo em seu convívio social. Em um universo mitológico, a cerâmica demanda uma forte carga representativa, pois os cerimoniais e rituais que fortalecem a unidade mítica entre os indivíduos são mesclados por artefatos específicos de cerâmica.

Como fonte de estudo para os arqueólogos, a cerâmica é de vital importância, permitindo a análise e a compreensão da dinâmica social e cultural dos grupos horticultores antigos. Acredita-se que a cultura material é pensada dentro 
da ótica da representação, pois, segundo Funari, "é possível descobrir ou aproximar-se do que está oculto nas evidências materiais, levando em conta as ausências, as diferenças e semelhanças que constituem o padrão da cultura material em contextos específicos" [1].

A cerâmica, através de seu próprio eixo, acrescenta informações sobre a dinâmica no território ambiental. A escolha, seleção e organização do território para assentamento dos grupos sociais, os locais de coleta de argila, de confecção, de queima e de utilização são fundamentais para o entendimento do arqueólogo sobre o ambiente ocupado e o homem ocupador.

Em arqueologia, a principal metodologia utilizada para análise dos fragmentos de cerâmica é a quantificação e a caracterização. Para realizar inferências e análises, considerase o tratamento de superfície e a forma de fabricação. Através de estudos tecno-tipológicos e sobre dispersão espacial/ comportamental entende-se a dinâmica cultural e territorial dos grupos sociais. Nesse sentido, as evidências em contexto tornam-se de vital importância para o entendimento do sítio arqueológico.

As pesquisas realizadas até o momento nos sítios arqueológicos da região conhecida geograficamente como Vale do Taquari demonstram a relação entre a cerâmica e grupos portadores da Tradição tecnológica Tupiguarani.

Os sítios arqueológicos dos ceramistas encontram-se em planícies de inundação, associadas a cascalheiras. As planícies são extensas, variando de 300 metros a 3 quilômetros. No entanto, para esse estudo foram utilizados os dados das análises tecno-tipológicas nas cerâmicas relacionadas aos sítios RS T 101, 105, 107 e 110. Quanto as supostas épocas de ocupação, as datações em termoluminescência indicam um longo e intenso período de mobilidade cultural na região, revelando datas que vão do século VI ao XV. As datações foram realizadas através do LACIFID da Universidade de São Paulo.

\section{MATERIAL E MÉTODOS}

A metodologia desenvolvida para aplicação dos dados partiu da análise tecno-tipológica [2] e da reconstrução gráfica, baseada em identificação da inclinação e diâmetro da borda. A partir dessa metodologia foi possível evidenciar cinco classes principais de vasilhas: panelas; caçarolas; pratos (para comer e assar); jarros; tigelas. No sítio RST 101 identificou-se 84 vasilhas de classes diferentes, no RST 105, 32 vasilhas de classes diferentes, no RST 107, 27 vasilhas de classes diferentes, no RST 110, 27 vasilhas, em um total de 170 tipos de vasilhas de classes diferentes. Exemplo de vasilha, Fig. 12.

A análise tecno-tipológica consiste na separação dos fragmentos quanto a sua borda, parede e base. Ao promover os trabalhos com as bordas, paredes e bases identificamse características como o tratamento de superfície e forma de produção. Para a análise das bordas também são identificados a inclinação e o diâmetro. No estudo do tratamento de superfície considera-se a parte externa do fragmento, que pode apresentar variações estilísticas em sua forma finalizada. A seguir, parte-se para uma descrição dos tratamentos de superfícies mais correntes na coleção cerâmica da região do Vale do Taquari/RS. A caracterização dos fragmentos foi realizada conforme os trabalhos de $\mathrm{La}$ Salvia e Brochado, 1989 [2].

O tratamento de superfície corrugado é considerado um demarcador dos grupos ceramistas Tupiguarani. O corrugado é caracterizado pela "ação lateral do dedo sobre a superfície cerâmica, pressionando uma parte da argila, por arraste, e formando uma crista de forma semi-lunar como resultado do acúmulo de argila arrastada" [2]. Aparece somente na face externa, associado a face interna lisa e raras vezes pintada.

O tratamento de superfície ungulado consiste na expressão decorativa da ação frontal da unha, na forma de um arco, com sentido e formato de quem aplica. Aparece na face externa e a parte interna é alisada.

$\mathrm{O}$ tratamento de superfície liso consiste no alisamento com auxílio de uma pedra (brunidor), madeira ou a própria mão de quem produz. Este objeto é friccionado na parte interna ou externa da vasilha, deixando a superfície lisa. Ainda, o tratamento pode ser elaborado através do banho da vasilha em uma argila mais plástica do que a utilizada na sua produção (tratamento de engobo). $\mathrm{O}$ tratamento de superfície liso pode receber pintura na face interna e externa.

Outro caso de tratamento de superfície é o roletado. O método de fabricação típico tupi-guarani utilizado pelas oleiras eram os cordéis de argila sobrepostos, conhecidos como roletes. Poucas vezes esses cordéis eram deixados expostos semnenhum tratamento de superfície complementar. No entanto, em nossas coleções de cerâmica arqueológicas esse tipo aparece com certa freqüência, o que nos possibilita classificar como mais um tratamento de superfície. Figuram na face externa, com interior alisado e raramente pintado.

Entre outros tratamentos superficiais, o pintado - considerado por La Salvia e Brochado [2] como um elemento de decoração - é aplicado na superfície lisa em ambas as faces. Muitas vezes encontra-se associado a outros tratamentos de superfície, porém ocorrendo em menor freqüência. A aplicação da pintura na cerâmica é realizada com tinturas orgânicas e minerais.

Os fragmentos de borda recebem um tratamento de alisamento e finalização especial na parte superior. Este alisamento recebe o nome de lábio, mostrando-se determinante na diferenciação da parede e da borda. O lábio é a parte superior da borda, que recebe um tratamento final de alisamento, deixando bem evidente a separação entre o resto da peça. Os tipos de lábio podem ser enquadrados em três categorias: aplanado, quando o lábio fica plano, apontado, quando o lábio é pressionado ficando com aspecto de ponta, arredondado, quando o lábio é alisado, ficando semi-circular.

Em última instância, analisando as coleções cerâmicas foi possível descrever os tipos de fragmentos cerâmicos encontrados. Nelas encontram-se as paredes, sendo estas os fragmentos de cerâmica sem lábio e borda. As bordas são fragmentos que apresentam lábios identificando a parte 
superior da vasilha. As bases indicam o fundo da vasilha. Alguns fragmentos apresentam a junção destes três tipos.

Segundo as respostas obtidas através do estudo tecnotipológico da coleção, as bordas enquadram-se em três categorias: infletidas, introvertidas e extrovertidas. Quanto à primeira, percebe-se que sua abertura e borda estão em posição vertical à parede. A segunda apresenta abertura e borda inclinadas à direção interna do objeto. A última é definida por uma inclinação das bordas direcionadas para fora.

Somente com os fragmentos de borda é possível visualizar o tamanho da vasilha. Isso porque, a técnica utilizada para definição é a medição do diâmetro. O diâmetro é medido através do bordômetro.

Seguindo o que propõem a análise tecno-tipológica, o acordelado é a principal forma de produção das vasilhas confeccionadas por grupos da tradição tecnológica tupiguarani. Em sua definição, é a produção de cordéis de argila sobrepostos, dando assim forma ao pote. Outro modo de fabricação das vasilhas, porém em menor escala, é o moldado. Em linhas gerais, é a aplicação de uma porção de argila dentro de um molde pré-fabricado. Encontra-se ainda a técnica do modelado na confecção de vasilhas, cuja definição é a utilização de uma porção de argila modelada com os dedos para dar forma a vasilha.

$\mathrm{O}$ estudo dos fragmentos cerâmicos dedica-se a entender os processos ocorridos após o abandono do assentamento. Na cerâmica o grau de conservação de superfície consiste em avaliar o estado físico do fragmento ou da peça. Os níveis de conservação são organizados em três categorias: conservada - quando se identifica o tratamento de superfície -, semi-erodida - quando apenas parte da peça $(+$ ou $-50 \%)$ se encontra desgastada - e erodida - quando não é possível identificar o tratamento da face externa, mesmo que a face interna esteja bem preservada.

\section{RESULTADOS}

Através da análise do material cerâmico foi possível comprovar a predominância da técnica do acordelamento na fabricação das vasilhas. Em nossas coleções, estudadas até o momento, $99 \%$ dos fragmentos enquadram-se na técnica referida.

Estudando os fragmentos, detectaram-se algumas características presentes na pasta. Esta, em geral, apresenta coloração variada, predominando a coloração cinza escura e marrom avermelhada na superfície, devido à queima oxidante incompleta, porém bem controlada, resultando numa vasilha de boa qualidade.

No que concerne ao estudo prévio da composição da argila, que apresenta-se bastante plástica identificou-se a presença de grãos de hematita (óxido de ferro), material orgânico e caco moído.

Quanto ao acabamento da superfície interna o alisado é o mais comum. No tratamento corrugado, os fragmentos da coleção apresentam algumas peças com pintura interna vermelha.

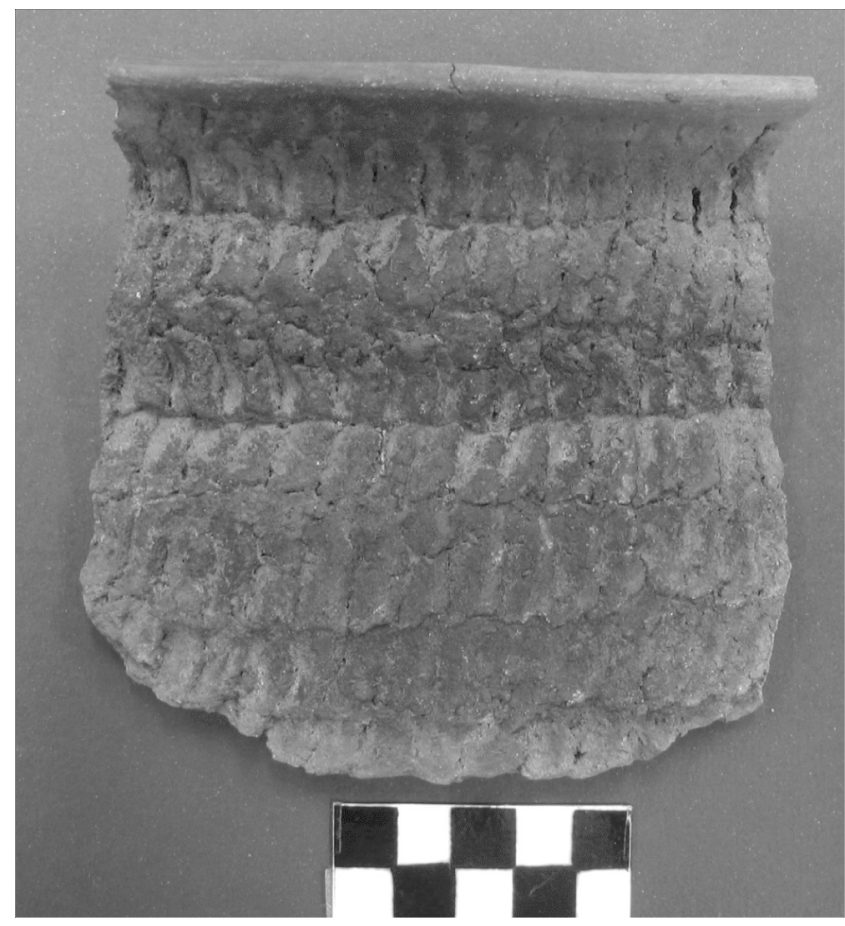

Figura 1: Caracterização do tratamento de superfície corrugado da coleção de evidências arqueológicas cerâmicas do Vale do Taquari/RS.

[Figure 1: Characterization of the corrugated treatment of surface of the collection of ceramic archaeological evidences of the Valley of the Taquari/RS.]

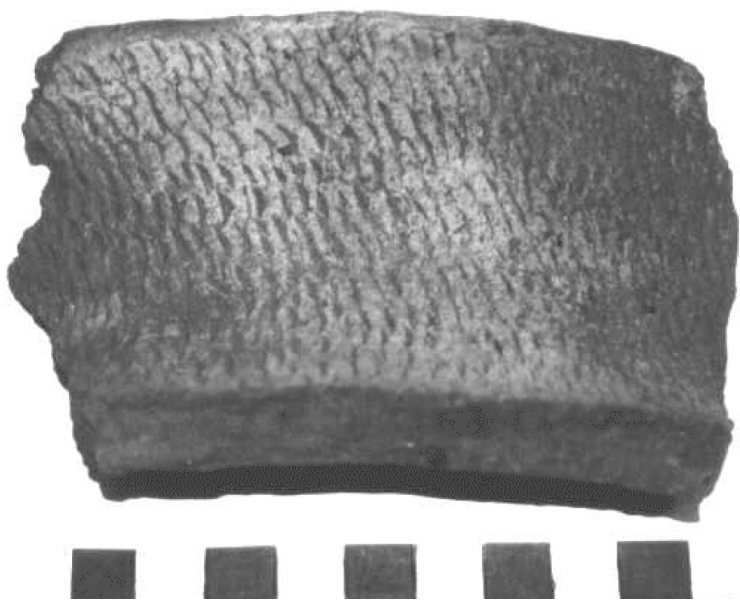

Figura 2: Caracterização do tratamento de superfície ungulado da coleção de evidências arqueológicas cerâmicas do Vale do Taquari/RS.

[Figure 2: Characterization of the ungulado treatment of surface of the collection of ceramic archaeological evidences of the Valley of the Taquari/RS.]

Os fragmentos cerâmicos ungulados da coleção apresentam o modelo simétrico e o assimétrico.

Os fragmentos lisos do Vale do Taquari têm suas faces interna e externa bem alisadas.

A junção de tratamentos de superfície é identificada nos 


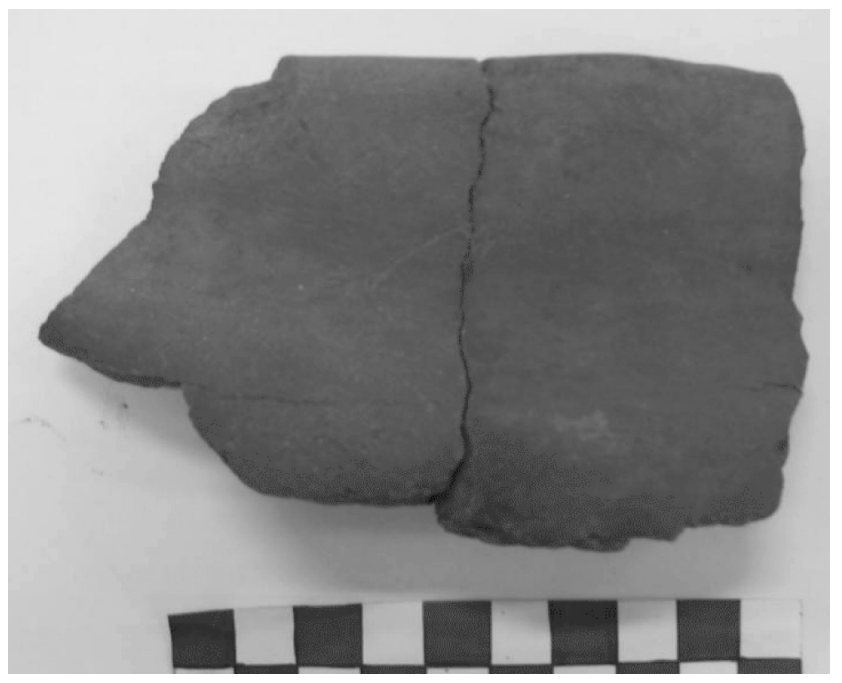

Figura 3: Caracterização do tratamento de superfície liso da coleção de evidências arqueológicas cerâmicas do Vale do Taquari/RS. [Figure 3: Characterization of the smooth treatment of surface of the collection of ceramic archaeological evidences of the Valley of the Taquari/RS.]

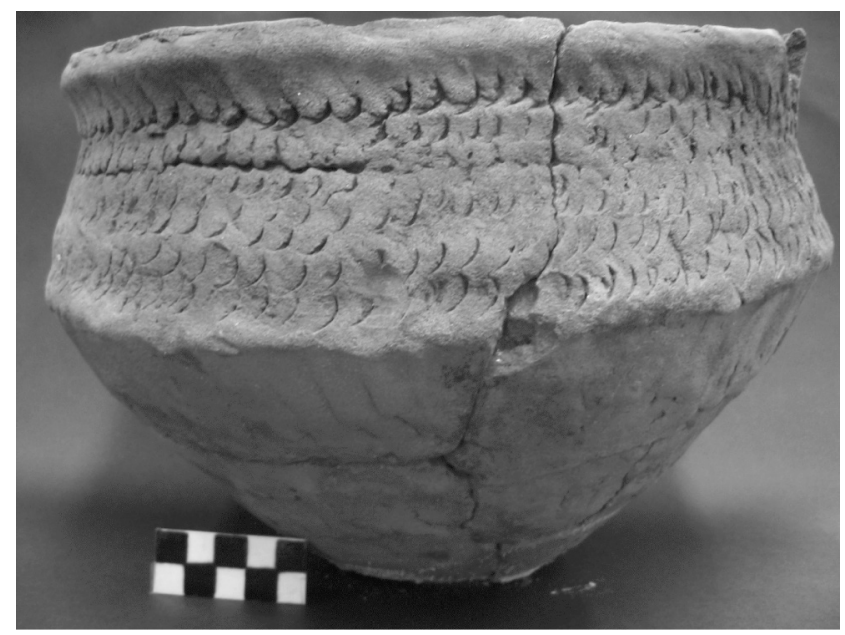

Figura 4: Caracterização da junção de tratamento de superfície corrugado, ungulado e liso da coleção de evidências arqueológicas cerâmicas do Vale do Taquari/RS.

[Figure 4: Characterization of the junction of corrugated, ungulado and smooth treatment of surface of the collection of ceramic archaeological evidences of the Valley of the Taquari/RS.]

fragmentos cerâmicos da coleção. Como exemplo, podese citar a junção do tratamento de superfície liso com o ungulado, do ungulado com rolete exposto, do corrugado com o ungulado e o liso com o corrugado, vide características especificas de cada tratamento supra-citadas.

$O$ roletado aparece na face externa com face interna alisada. A coleção apresenta alguns fragmentos com os roletes expostos na parte superior próximo à borda e outros perto da base.

Quanto aos fragmentos pintados, notam-se algumas variações como a cor banca, preta e vermelha. $\mathrm{O}$ tratamento

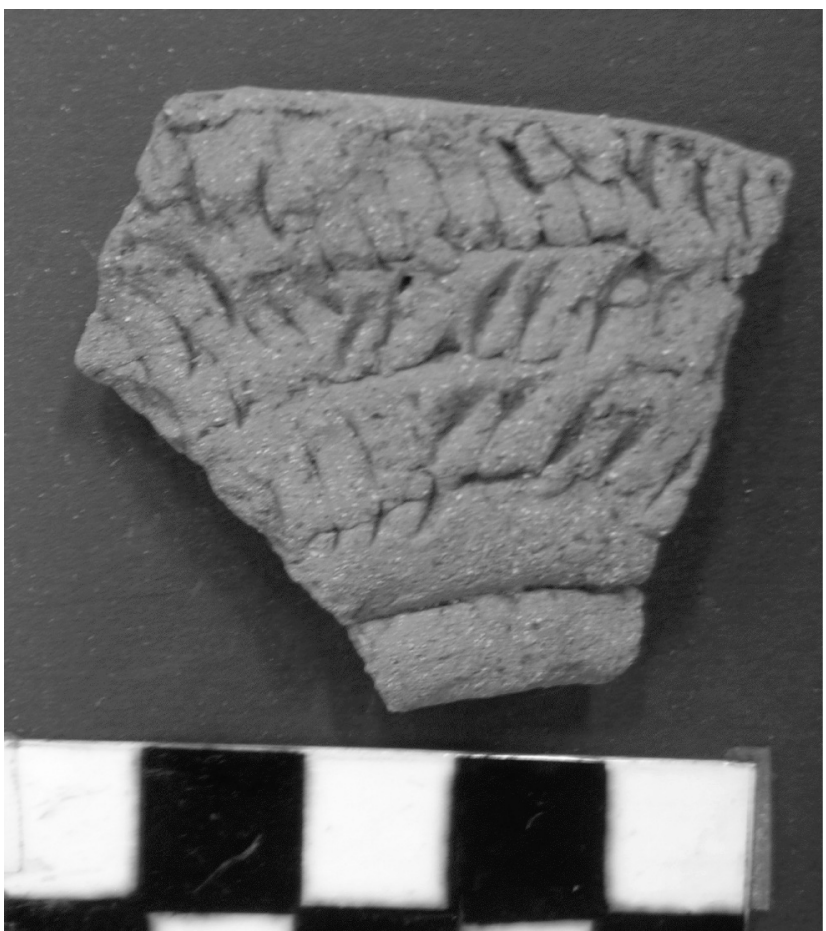

Figura 5: Caracterização do tratamento de superfície com rolete evidente, coleção de evidências arqueológicas cerâmicas do Vale do Taquari/RS.

[Figure 5: Characterization of the treatment of evident surface with rolete, collection of ceramic archaeological evidences of the Valley of the Taquari/RS.]

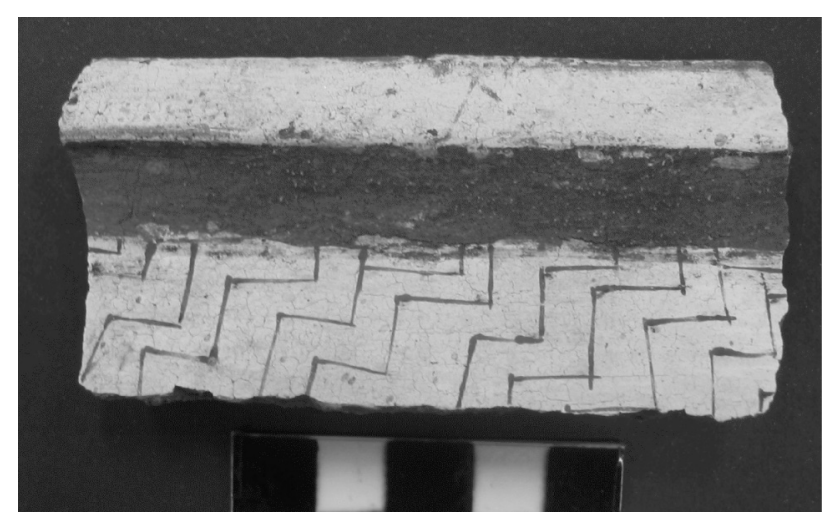

Figura 6: Caracterização do tratamento de superfície com pintura externa, fundo branco, faixa vermelha e desenhos geométricos de conjunto de linhas em zigue-zague vermelhas. Coleção de evidências arqueológicas do Vale do Taquari/RS.

[Figure 6: Characterization of the treatment of surface with external painting, deep white, red band and geometric drawings of set of red lines in zigzag. Collection of archaeological evidences of the Valley of the Taquari/RS.]

pode aparecer em todo o pote, mas normalmente ocorre na parte superior, interna ou externamente. Geralmente, os desenhos geométricos são delineados com a cor branca ou vermelha no fundo. São freqüentes ainda faixas vermelhas de larguras variadas circundando a vasilha. Tradicionalmente, 


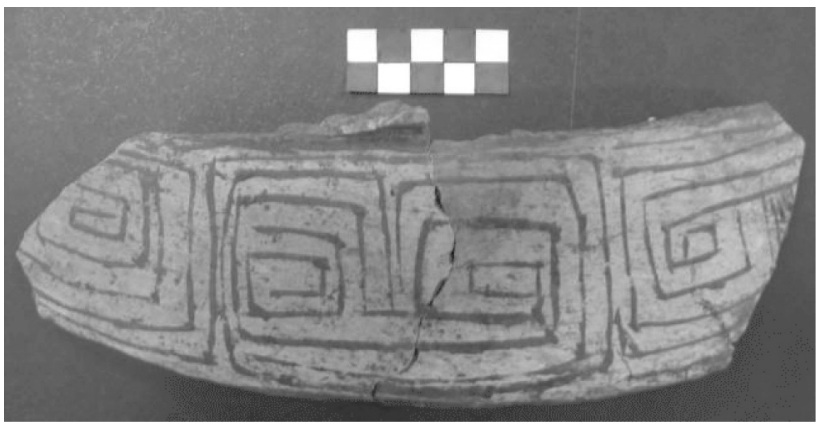

Figura 7: Caracterização do tratamento de superfície com pintura externa, fundo branco, faixa vermelha e desenhos geométricos em vermelho. Coleção de evidências arqueológicas do Vale do Taquari/RS.

[Figure 7: Characterization of the treatment of surface with external painting, deep white, red band and geometric drawings in red. Collection of archaeological evidences of the Valley of the Taquari/RS.]

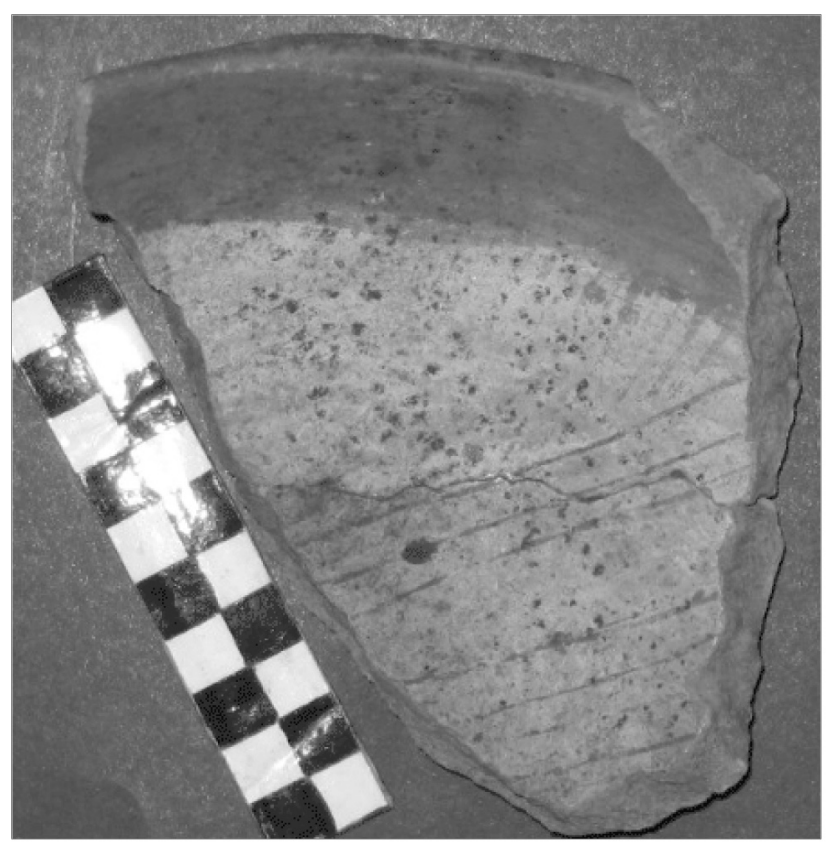

Figura 8: Caracterização do tratamento de superfície com pintura interna, fundo branco, faixa vermelha e desenhos geométricos em preto. Coleção de evidências arqueológicas do Vale do Taquari/RS.

[Figure 8: Characterization of the treatment of surface with internal painting, deep white, red band and geometric drawings in black color. Collection of archaeological evidences of the Valley of the Taquari/RS.]

relaciona-se cerâmica pintada aos grupos tupiguarani e estas teriam, em sua essência, uma presente função em rituais. A coleção apresenta vasilhas pintadas com diâmetro de borda variando de 15 a $31 \mathrm{~cm}$.

Como já dito, as bordas enquadram-se em três categorias - bordas infletidas, introvertidas e extrovertidas. Na coleção arqueológica do Vale do Taquari essas três categorias estão presentes.

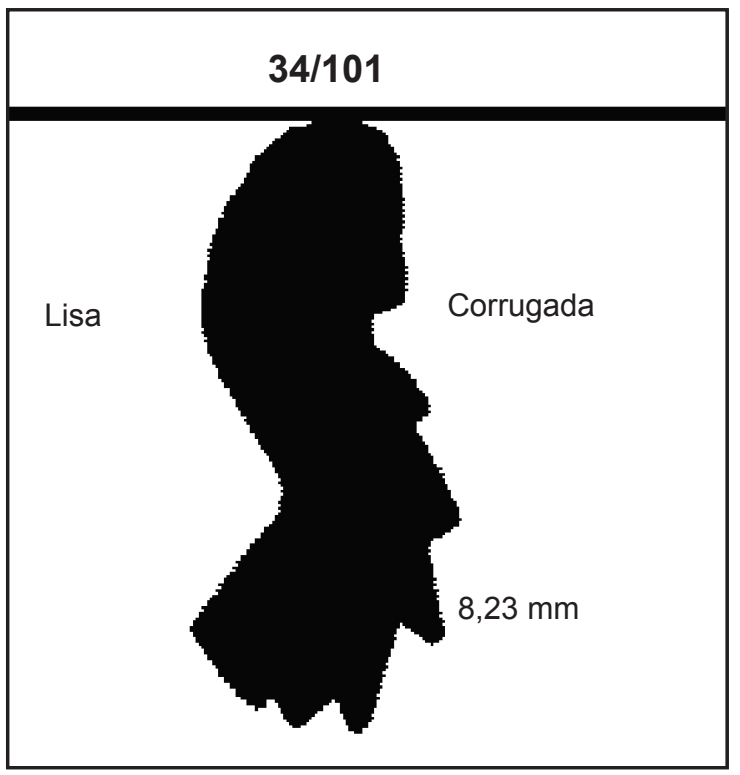

Figura 9: Caracterização do tipo de borda, extrovertida. Coleção de evidências arqueológicas do Vale do Taquari/RS.

[Figure 9: Characterization of the type of edge, extrovert. Collection of archaeological evidences of the Valley of the Taquari/RS.]

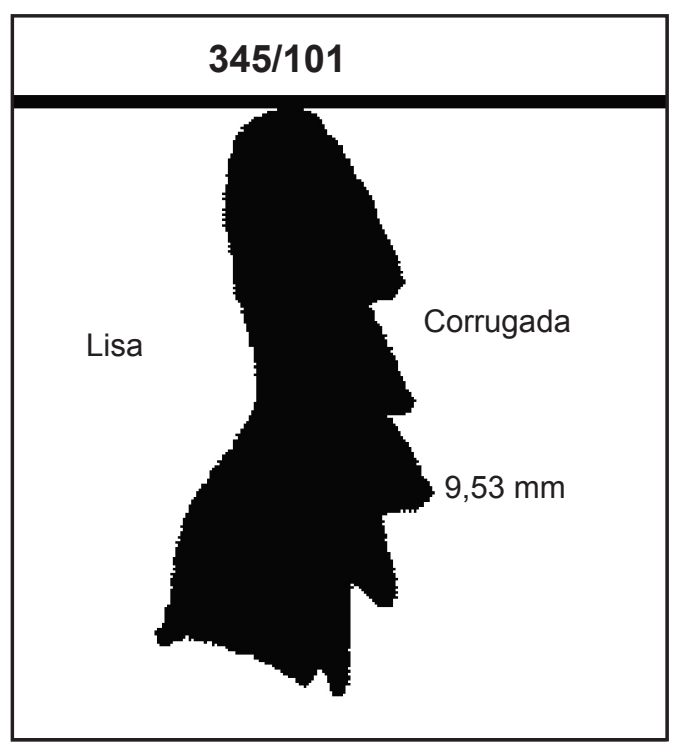

Figura 10: Caracterização do tipo de borda, introvertida. Coleção de evidências arqueológicas do Vale do Taquari/RS.

[Figure 10: Characterization of the type of edge, introvert. Collection of archaeological evidences of the Valley of the Taquari/RS.]

Em bordas nas quais é possível verificar medidas de diâmetro, as aberturas da boca apresentam médias de 20 $\mathrm{cm}$, variando de $+/-8 \mathrm{a}+/-40 \mathrm{~cm}$. Entretanto, no total de bordas de cada sítio apenas alguns fragmentos com tamanho superior a $5 \mathrm{~cm}$ possibilitaram a identificação do diâmetro. No sítio RS T 101, das 92 bordas foi possível verificar o diâmetro de 42 . No sítio RS T 105, totalizando 32 bordas identificou-se o diâmetro de 12 . No sítio RS T 107, de 


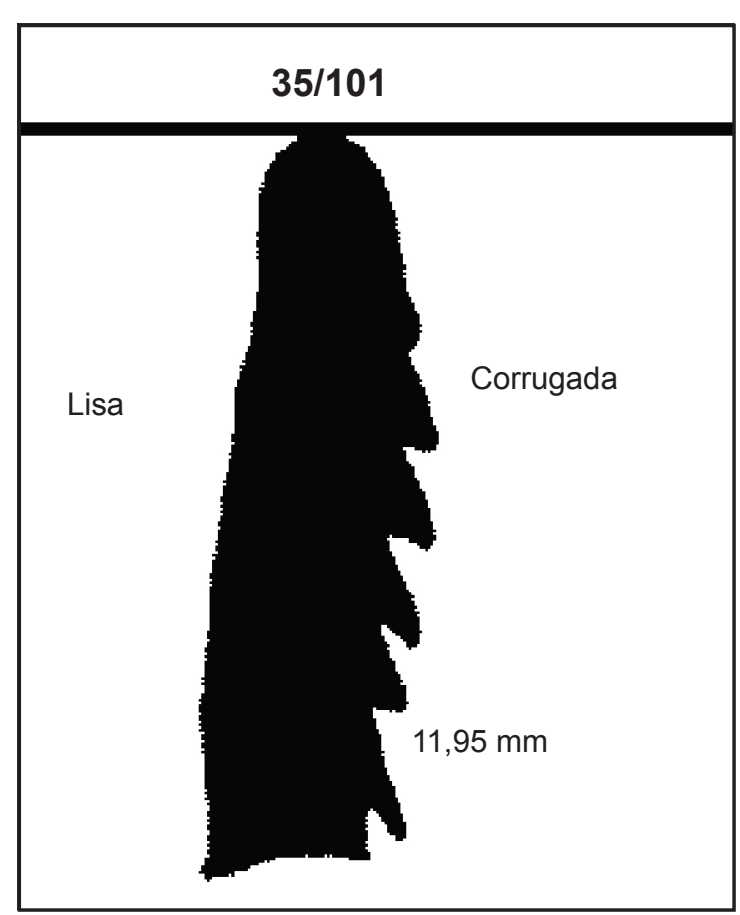

Figura 11: Caracterização do tipo de borda, infletida. Coleção de evidências arqueológicas do Vale do Taquari/RS.

[Figure 11: Characterization of the type of edge, inflected. Collection of archaeological evidences of the Valley of the Taquari/RS.]

Diâmentro +/- 17 1545/101

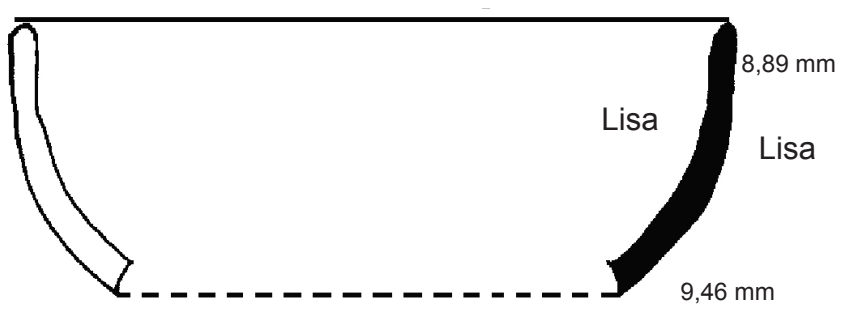

Figura 12: Desenho de borda de onde foi possível tirar a medida do diâmetro. Coleção de evidências arqueológicas do Vale do Taquari/RS.

[Figure 12: Drawing of edge of where it was possible measure the diameter. Collection of archaeological evidences of the Valley of the Taquari/RS.]

45 bordas mediu-se o diâmetro de 32 . No sítio RS T 110 apenas 2 bordas num conjunto de 21 tiveram seu diâmetro reconstituído. Conforme Rogge (1996:98) [3] as formas podem ser de panelas de servir e cozer alimentos, aparecendo ainda algumas tigelas. Porém, a maioria das vasilhas indica uma função de cozer, com lábios arredondados e infletidos.

Os fragmentos de lábio apresentam os três tipos de finalização: 43,4\% aplanado, 13,6\% apontado e 43,7\% arredondado. Dos fragmentos identificados $76 \%$ são de paredes, 22,9\% são de borda e 1,1\% de base. As bases são em sua maioria arredondadas, ou, às vezes, levemente cônicas. Os fragmentos apresentam-se bem preservados, em média superior a $5 \mathrm{~cm}$ de largura. Do total de peças, 3,38\% estão erodidas, 5,08\% estão semi-erodidas e 91,69\% estão conservadas.

\section{CONCLUSÕES}

Conforme a posição dos sítios arqueológicos, localizados nas margens do rio Forqueta, afluente do rio Taquari e levando em consideração a proximidade entre os sítios que margeiam o Forqueta, uma de nossas principais hipóteses é que estamos tratando de um mesmo grupo étnico e cultural o qual ocupou por muitos séculos a região.

Segundo bibliografias referentes ao assunto, alguns grupos humanos pré-coloniais deslocavam-se por grandes áreas na busca de alimentos, matérias-prima para cerâmica, lítico, vestimentas e construção de moradias. As evidências cerâmicas apresentam-se dispersas em grandes extensões do terreno, tratando-se, possivelmente, de uma região regada de aldeias de horticultores. No entanto, não se descartam os elementos pós-deposicionais que ocorrem em um sítio arqueológico. A perturbação intensa da flora e da fauna regional, assim como os constantes trabalhos agrícolas desenvolvidos no local contribuem para a modificação do sítio arqueológico, e são responsáveis, na grande maioria das vezes, pela retirada do material de seu contexto original, dificultando a interpretação mais precisa da dinâmica social e cultural do sítio.

Outro fator que reforça a suposição de se tratar de um grupo horticultor, é a analise do ambiente natural sem as fronteiras políticas atuais. As características ambientais que condicionam a captação de recursos e a semelhança entre os materiais encontrados e os confeccionados por horticultores, como os conhecidos Guarani, enaltecem a hipótese de estar se falando de grupos que praticavam horticultura.

O material é encontrado nos diferentes sítios que se localizam nas margens do referido rio, praticamente nas mesmas condições, havendo grande concentração de material nas manchas pretas do terreno - indicando ação humana tanto na superfície quanto nos terraços fluviais.

A cerâmica, coletada juntamente com sedimento entre os níveis 20 e $30 \mathrm{~cm}$ de profundidade, no talude do rio, foi enviada para análise termoluminescente no LACIFID da Universidade de São Paulo. Os resultados apresentados foram os seguintes: a amostra da cerâmica possui 1099 anos, portanto a última incidência de calor, então de queima, foi efetuada no ano de 906 DC. A informação está de acordo com o período aceitável para a ocupação Guarani no Rio Grande do Sul, assim como as datas se aproximam das ocupações identificadas nos Vale do Rio Pardo e Jacuí [3].

$\mathrm{Na}$ análise do material cerâmico, abordam-se, normalmente, aspectos da produção com a função do objeto pré-definida, decoração e forma específica para cada função do objeto. Nesse sentido, é possível estabelecer a função de determinado objeto cerâmico sem uma confrontação com dados etnográficos e estabelecerum padrão de comportamento para um grupo. Excluir totalmente as exceções e também a subjetividade do comportamento de cada indivíduo, sendo 
que mesmo em objetos similares em forma e decoração, permanece a marca individual. Não se analisa o ser humano que produz e não se observa a singularidade de cada peça. Define-se o pensamento humano na produção dos recipientes, limitando a individualidade, dentro de um grupo, ou melhor, dentro de "indústria" de produção. Indústria, praticada conforme as necessidades do grupo, visando a praticidade na utilização destes recipientes. Obviamente, a relação com os "padrões" de comportamento da sociedade atual, interfere de maneira negativa, em uma conclusão a respeito deste assunto. Porém será mesmo necessária uma conclusão sobre esse assunto? Não basta saber que guardavam alimentos, acondicionavam líquidos, cozinhavam e que utilizavam materiais feitos de cerâmica? E onde coletavam a argila, onde produziam os vasilhames? É realmente fundamental saber o que era usado para determinado fim? Estar-seá reduzindo um ambiente complexo de comportamento em minúcia. Parece suficientemente complexo analisar o fato de que sabiam exatamente que tipo de matéria prima utilizar, que materiais adicionar e excluir e identificá-los em laboratório, para depois em campo saber onde eram coletados, verificando a dinâmica do grupo no território.

Classifica-se o material cerâmico quanto ao seu tratamento de superfície, separando-se os diferentes tipos. Porém, será que cada tratamento possuía um fim pré-determinado? Cada forma exigindo um determinado tratamento de superfície, as exceções são totalmente excluídas neste tipo de análise.

O fundamento da arqueologia é a análise do objeto produzido e alterado pela mão humana. Ao arqueólogo cabe identificar as diferentes evidências deixadas e preservadas pelo tempo, a técnica utilizada na confecção destas evidências, a proveniência das matérias-prima, a dinâmica do grupo no território, a área de ocupação, inferir sobre uma possível função e utilização destes objetos, porém dificilmente conseguirá através destes objetos a descrição do comportamento "social", a hierarquia, o sistema familiar destes grupos.

\section{REFERÊNCIAS}

[1] P. P. A. Funari, Arqueología e Historia, Arqueología Histórica mundial y de América del Sur, Anales de Arqueología y Etnología, Mendoza 50-51 (1999) 109-132. [2] F. La Salvia, J. P. Brochado. Cerâmica Guarani, Posenato Arte e Cultura, Porto Alegre, RS (1989).

[3] J. H. Rogge, Adaptação na floresta subtropical: a tradição Tupiguarani no médio rio Jacuí e no rio Pardo, Arqueologia do Rio Grande do Sul, Documentos 06, Instituto Anchietano de Pesquisas, S. Leopoldo RS (1996).

[4] M. Albuquerque, CLIO, Revista do Curso de Mestrado em História da UFPE, Série Arqueológica (1990) 81.

[5] M. Albuquerque, CLIO - Série Arqueológica, Revista do Curso de Mestrado em História da UFPE, número extraordinário dedicado aos Anais do I Simpósio de Préhistória do Nordeste Brasileiro (1991) 121.

[6] I. Hodder, Arqueología Espacial: Colóquio sobre distribución y relaciones entre los asentamientos, Teruel (1984) 7.

[7] S. Klamt, Uma contribuição para o sistema de assentamento de um grupo horticultor da Tradição Cerâmica Tupiguarani, Série Conhecimento, 29 Ed. UNISC, Santa Cruz do Sul (2005).

[8] J. L. Morais, Perspectivas Geoambientais da Arqueologia do Parapanema Paulista, Tese de Livre-Docência, USPMAE, S. Paulo (1999).

[9] N. T. G. Machado, Relatório final para IPHAN, ref. Portaria n. 59 de 14 de maio de 2004.

[10] J. H. Rogge, Fenômenos de fronteira: um estudo das situações de contato entre os portadores das tradições cerâmicas pré-históricas no Rio Grande do Sul, Tese de Doutoramento, Unisinos, S. Leopoldo, RS (2004).

[11] A. L. R. Soares, Contribuição à Arqueologia Guarani: Estudo do Sítio Ropke, Vol. 1, Ed. UNISC, Santa Cruz do Sul (2005).

(Rec. 08/08/2007, Rev. 30/10/2007, Ac. 27/12/2007) 